\title{
Factors Influencing Intern Performance and Employability in Sport Management: A Voice from Internship Site Supervisors
}

\author{
Simon M. Pack \\ St. John's University, New York, USA
}

\begin{abstract}
Recent literature refers to internships as one of the most impactful aspects of an academic degree program and a catalyst for developing necessary employability skills (Narayanan, Olk, \& Fukami, 2010; Shoenfelt, Stone, \& Kottke, 2013). The purpose of this study was to utilize internship site supervisor evaluations to assess interns' skills, knowledge, and ability as a means of gaining a greater understanding of employability in the sport industry.
\end{abstract}

Keywords: internships, employability, sport management

\section{Article History}

Received 20 September 2020

Accepted 22 September 2020

Published 31 January 2021

Available online 19 February 2021

https://doi.org/10.47544/johsk.2021.2.1.37

\author{
Corresponding Author \\ Simon M. Pack \\ packs@stjohns.edu \\ Department of Sport Management \\ The Lesley H. \& William L. Collins College of Professional Studies \\ St. John's University, New York, USA
}

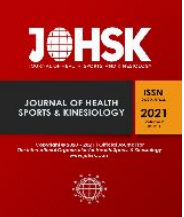

\section{Methods \& Results}

A total of 420 usable, final supervisor evaluations were gathered from the academic years 2012-2013 through 2018 2019. Interns' quality of work $(\beta=.49, p<.001)$ was the most important predictor in explaining their performance as an intern, followed by their attitude $(\beta=.20, p<.001)$, dependability $(\beta=.12, p=.002)$, quality of oral communication $(\beta=.10, p<.001)$ and maturity $(\beta=.07, p=.015)$. Similarly, interns' quality of work $(\beta=.37, p<.001)$ was the most important predictor for their employability, followed by attitude $(\beta=.24, p<.001)$, quality of oral communication $(\beta=.15, p<.001)$ and quality of writing $(\beta=.09, p=.020)$.

\section{Conclusion}

Students, higher education institutions and industry practitioners are in a constant flux between what is offered within the sport management curriculum and what is required by the sport industry (Emery et al., 2012). Other scholars (e.g., de Schepper et al., 2020) also found this as a challenging balance between developing wellrounded graduates and providing appropriate sport management job opportunities.

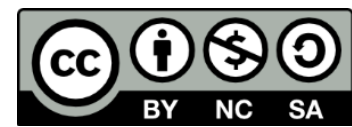

(C) 2021. This work is licensed under a CC BY-NC-SA 4.0 International license. This is an open access article distributed under the Creative Commons Attribution License which permits unrestricted use, distribution, and reproduction in any medium, provided the original work is properly cited.

Journal of Health, Sports, \& Kinesiology | ISSN 2692-9864 | www.johsk.com 